\title{
Um die Naturheilkunde kommt keiner herum
}

In MMW 16 wollten wir wissen, welchen Stellenwert die Naturheilkunde in der Praxis unserer Leser hat. Das Ergebnis unserer Umfrage: Die meisten Ärzte werden tagtäglich von Patienten auf naturheilkundliche Therapieoptionen angesprochen und setzen sie auch in einem breiten Spektrum von Indikationen ein.

Knapp $80 \%$ der teilnehmenden Ärzte geben an, dass ihre Patienten häufig bis sehr häufig nach Therapien aus dem Bereich der Naturheilkunde fragen (siehe Abbildung). Weitere $12 \%$ erhalten zumindest gelegentlich solche Anfragen. Besonders großes Interesse besteht nach Auskunft der Ärzte beispielsweise bei Müttern mit kranken Kindern und bei chronisch kranken Patienten.

\section{Die häufigsten Indikationsgebiete}

Der Umfrage zufolge wenden 98\% der Ärzte in ihrer Praxis (ergänzend) naturheilkundliche Verfahren an, und zwar vorrangig die Phytotherapie. Am häufigsten kommt die Naturheilkunde bei Infekten und Infektanfälligkeit zum Einsatz; Infektionen der Atemwege stehen dabei an erster Stelle. Weitere wichtige Indikationsgebiete sind demnach gastrointestinale Beschwerden (z.B. Reizdarm), Schmerzen, Allergien, Erschöpfung, Schlafstörungen und Depressionen. 7\% der Ärzte geben an, Naturheilkunde in allen Indikationen einzusetzen.

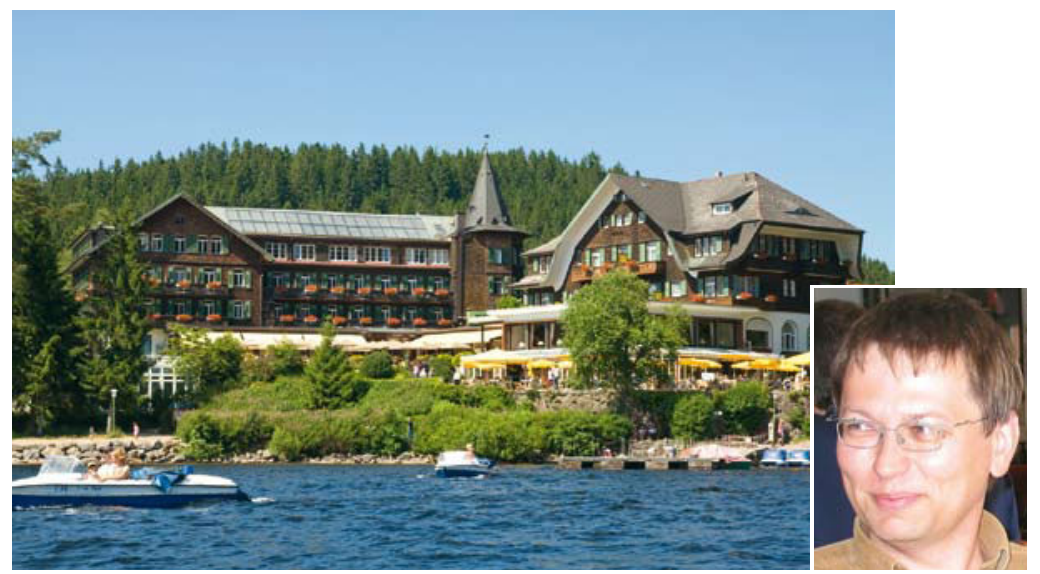

\section{Abbildung}

Wie oft fragen Ihre Patienten nach naturheilkundlichen Therapien?

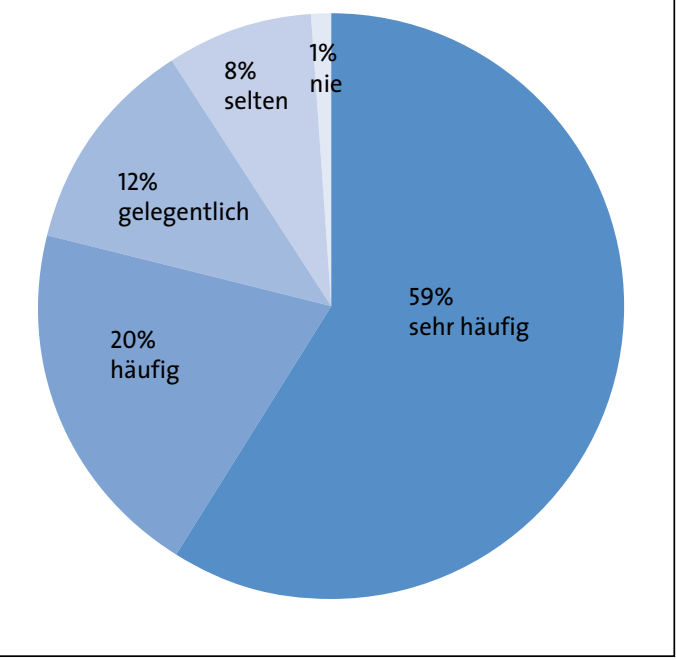

\section{Wir gratulieren!}

Als Dankeschön haben wir unter den Teilnehmern der Umfrage wertvolle Preise verlost.

Gewinner des Wellness-Wochenendes in Treschers Schwarzwaldhotel am See ist Herr Dr. Christoph Hertrich, Facharzt für Allgemeinmedizin aus Bamberg (Foto).

Die 14 Gewinner der Springer-Bücher „Arzneitherapie für Ältere“ und „Häufige Hautkrankheiten in der Allgemeinmedizin“ wurden schriftlich benachrichtigt. 